https://doi.org/10.30910/turkjans.556618

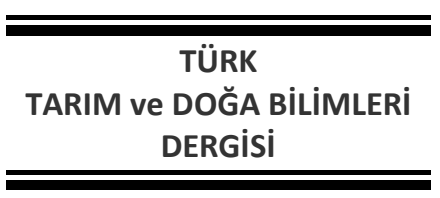

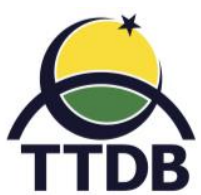

www.dergipark.gov.tr/turkjans

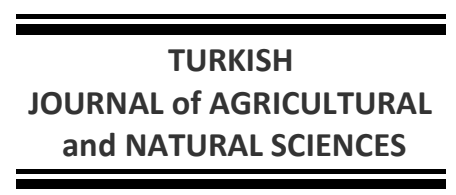

Araştırma Makalesi

\title{
Sulama Suyu Tuzluluğunun Eski ve Yeni İki Sıralı Arpa (Hordeum vulgare conv. distichon) Çeşitlerinin Çimlenmesi Üzerine Etkileri
}

Gizem KUNT, İsmail TAŞ*

Çanakkale Onsekiz Mart Üniversitesi. Ziraat Fakültesi. Tarımsal Yapılar ve Sulama Bölümü, Çanakkale

*Sorumlu yazar: tas_ismail@yahoo.com

Geliş Tarihi: 03.10.2018

Düzeltme Geliş Tarihi: 16.02.2019

Kabul Tarihi: 25.02.2019

Özet

$\mathrm{Bu}$ araştırmada ilk kültüre alınan bitkilerden olan arpanın, iki sıralı türüne ait eski (Cumhuriyet) ve yeni (İnce 04) geliştirilmiş iki çeşidinin, tuzlu sulama suyu koşullarında çimlenme özellikleri incelenmiştir. Sulama suyu Elektriksel İletkenlik (ECi) değerleri 0, 2, 4, 6, 8, 12 ve $16 \mathrm{dS} / \mathrm{m}$ olacak şekilde ve de Sodyum Absorbsiyon Oranı (SAR) 3'ten küçük olacak biçimde hazırlanmıştır. Çalışma sonunda elde edilen verilere yapılan varyans analizine göre, sulama suyu tuzluluğunun, söz konusu arpa çeşitlerinin çimlenme hızı ve çimlenme gücü üzerine \%5 önem düzeyinde etkili olduğu belirlenmiştir. Sulama suyunda artan EC değerine karşılık, arpa çeşitlerinin çimlenme hızı ve çimlenme gücü azalmıştır. Çalışmada elde edilen sonuçlara göre, yeni geliştirilen arpa çeşidi olan İnce 04 'ün ECi değerinin 12 $\mathrm{dS} / \mathrm{m}$ seviyesine kadar çimlenme açısından tolerans gösterdiği belirlenirken, eski çeşit olan Cumhuriyet çeşidinin ise $8 \mathrm{dS} / \mathrm{m}$ EC değerine kadar tolerans gösterdiği tespit edilmiştir.

Anahtar kelimeler: Elektriksel iletkenlik, SAR, arpa.

\section{Effects of Irrigation Water Salinity on Germination of Old and New Barley (Hordeum vulgare conv. distichon) Species}

\begin{abstract}
The old (Cumhuriyet) and new (Ince04) developed varieties of the two rows of the barley, one of the first cultivated plants, were subjected to the germination test under saline irrigation water conditions. Irrigation water Electrical Conductivity (ECi) values are $0,2,4,6,8,12$ and $16 \mathrm{dS} / \mathrm{m}$ and Sodium Absorption Rate (SAR) is prepared to be less than 3. According to the analysis of the variance made to the data obtained at the end of the study, irrigation water salinity, the rate of germination and the germination power of these barley varieties were determined to be effective on the level of $5 \%$ importance. In spite of increasing EC value in irrigation water, the germination rate and the germination power of the barley varieties decreased. Result of this study, it has been determined that Ince 04, new development kind of barley, is resistant salinity water about $12 \mathrm{dS} / \mathrm{m}$. Whereas, Cumhuriyet, old kind of barley, is resistant of salinity water about $8 \mathrm{dS} / \mathrm{m}$.
\end{abstract}

Key words: Electrical conductivity, SAR, barley.

\section{Giriş}

Dünya nüfusu sürekli artmakta ve buna bağlı olarak da su kaynakları hızlı bir şekilde kirlenmektedir. Artan su kirliliği, temiz su kaynakları üzerindeki baskının artmasına da neden olmaktadır. Kullanılabilir ve içilebilir su kaynaklarının hızlı bir şekilde azalması, özellikle temiz suya erişimin zor olduğu bölgelerde tarımsal faaliyetler için düşük kalitede su kaynaklarını 
kullanılabilir hale getirebilmek amacıyla yapılan araştırmaların artmasını zorunlu kılmaktadır. Yapılan çalışmalarda, başta sodyum tuzu olmak üzere, genel olarak tuzların her bitki ve toprak türüne göre farklı konsantrasyonlarda farklı etkiler yarattığı bilinmektedir. Yeterli ve gerekli önlemler alınmadığı durumlarda verimi düşüren ve toprağa zarar veren bir faktör olarak öne çıkmaktadır.

Sulama suyunun kalitesi sadece içerdiği toplam tuz miktarı ile değil aynı zamanda tuzların cinsi ile de değerlendirilir. Suyun toplam tuz içeriğinin artmasıyla toprak ve bitkiye ilişkin problemler ortaya çıkacaktır. Suyun kalitesi ya da kullanım için uygunluğu, suyun uzun dönem kullanımı ile ortaya çıkabilecek potansiyel problemlere bağlı olarak değerlendirilir. Sulu tarımda su kalitesine bağlı olarak yaygın şekilde karşılaşılan problemler dört ana başlık altında toplanabilir. Bunlar, bitki kök bölgesi tuzluluğu, suyun infiltrasyon oranı, özel iyon toksisitesi ve diğer problemlerdir (Ayers ve Westcot, 1994; Taş, 2017).

Bitkilerde ozmotik stres ve iyon stresi şeklinde ortaya çıkan tuzluluk stresi, büyüme ve gelişimi engelleyerek bitkide; yapısal, fizyolojik, biyokimyasal ve moleküler düzeylerde değişimlere yol açmaktadır (Çulha ve Çakırlar, 2011). Kuraklıktan sonra tarımsal üretimi en çok sınırlayan abiyotik stres faktörü tuzluluktur. Günümüzde dünya genelinde tarımsal üretim yapılan alanların yaklaşık \%15-20'si ve sulama yapılan tarım alanlarının ise yaklaşık \%20-50'si tuzluluktan olumsuz olarak etkilenmektedir (Benlioğlu ve Özkan, 2015). Ülkemizde bazı tuza dayanıklı bitkilerin yetiştirilmesine imkan veren hafif tuzlu toprakların kapladığı alan 614657 ha ile tüm arazilerimizin \%0.8'ini oluşturmaktadır. Üretime imkan vermeyen tuzlu topraklar 504603 ha ile \%0.6, sodik topraklar 8641 ha ile \%0.01, hafif tuzlu-sodik topraklar 123863 ha ile \%0.2, tuzlu sodik topraklar 264956 ha ile \%0.3 olmak üzere toplamı 1518722 ha olup \%2 düzeyindedir. Hafif tuzlu ve tuzlu toprakların kapladığı alan 1119260 ha'dır (Sönmez ve Beyazgül, 2008).

Toprakların tuzlanmasında tehlikeli olan doğal tuzlanma değildir. Tehlike, hatalı yapılan sulama, gübreleme ve diğer uygulamalar sonucu oluşan tuzlanmadır. Topoğrafik koşullar, toprak özellikleri ve bitkinin su isteği dikkate alınmadan yapılan düzensiz sulamalar, yarı kurak iklimlerde toprak tuzluluğunun oluşmasında en önemli kaynaklardandır (Taş ve Kırnak, 2001).

Kurak ve yarı kurak alanlarda sulu tarımın önemli bir sorunu olan bitki kök bölgesi tuzluluğu ve bu tuzluluğun dağılımı, araştırmacılar tarafından tüm dünyada yoğun olarak incelenmektedir. Sulamada tuzluluk yönetiminde bugün en önemli konulardan birisi, zaman boyutunda su kaynaklarımızın kalitelerinin sürekli kötüleşmesi sonucunda, hangi düzeydeki tuzluluğa izin verilebilir ve bu tür bir tuzluluk düzeyinde hangi yönetim önlemlerinin alınması gerekir sorusuna cevap aramaktır. Bitki kök bölgesine çeşitli kaynaklardan iletilen ve biriken tuzlar, çözelti ozmotik basıncının artmasına neden olmaktadır. Ozmotik basıncın artması ise bitkinin kök bölgesindeki suyu almasını güçleştirmekte ve konsantrasyona bağı olarak da engelleyebilmektedir (Maas ve Hoffman 1977; Taş, 2017).

Yüksek ve tuzlu bir taban suyu sorunu olmayan alanlarda, bitki kök bölgesinde biriken tuzların çok büyük bir bölümü sulama suyu ile iletilen tuzlardır. Bitki kullanımı ve evaporasyon ile tuzların çok küçük bir bölümü eksilmektedir. Kalan büyük çoğunluk, yıkama ile alandan uzaklaştırılmadığında bitki kök bölgesinde tuzluluğunun artmasına neden olur (Yurtseven ve Öztürk, 2001). Kök bölgesinde artan tuzluluk yapraklarda sararma ve solmaya, bitki turgorunda azalmaya ve görünümde de zayıflamaya neden olur. Uzun süre bu etki altında kalan bitkilerde kalıcı ve verimi etkileyen sonuçlar ortaya çıkar (Ayyıldız, 1990; Yurtseven, 1997).

Arpa, dünyada yetiştiriciliği yapılan tahılların başında gelip, insan tüketimi için kültüre alınan bitkilerdendir. Arpa, farklı çevre koşullarına iyi uyum sağlamaları nedeniyle diğer tahıllara nazaran daha geniş bir alanda üretilmektedir. Arpa, insan besin zincirine farklı yollardan girer. Birincisi, bir hayvan yemi olarak kullanılır ve bu nedenle, et üretimi yoluyla dolaylı olarak insan diyetine önemli bir katkı sağlar. İkincisi, özellikle bira olmak üzere alkollü içeceklerin üretimi için bir alt tabaka görevi görür. Üçüncü olarak, insanlar tarafından yenen çeşitli gıda maddelerini üretmek için az miktarda arpa kullanılır. FAO istatistikleri dikkate alındığında 2016/2017 üretim yılında arpa üretimi yaklaşık 148 milyon tondur. Arpa üretiminin yaklaşık üçte ikisi, düşük veya belirsiz yağış alanlarına girmektedir.

Tuz toleransı, bitkilerin tuzlu koşullar altında hayatta kalma ve gelişme döngüsünü tamamlayabilme yeteneği olarak tanımlanır ve farklı mekanizmaları içeren kompleks bir olaydır (Yıldız ve Terzi, 2011). Arpa tuzluluğa toleransı en fazla olan bitkilerden biridir.

Bitkilerin tuzluluğa toleransı karakteristik olmayıp, bitki büyüme evresine göre değişkenlik gösterebilir. Arpa diğer bitkilerden ziyade çimlenme ve genç fide safhalarında tuzluluğa daha duyarlıdır (Al- 
Karaki, 2001). Arpa çeşitlerinde tohum çimlenmesinin tuzluluk tarafından önlenmesinin sebebi ozmotik etkilere bağlanmıştır. Tahıllar ile yapılan diğer çalışmalar, tuzluluğun yol açtığı çimlenmenin ve fide gelişimindeki azalmaların, spesifik iyon toksisitesi kaynaklı olduğu ileri sürülmektedir. (Huang ve Redmann, 1995).

Ayers ve Westcot (1994)'e göre toprak saturasyon ekstraktı elektriksel iletkenlik $\left(E C_{e}\right)$ değeri $8 \mathrm{dS} / \mathrm{m}$ ve sulama suyu elektriksel iletkenlik $\left(E C_{i}\right)$ değeri $5,3 \mathrm{dS} / \mathrm{m}$ değerleri arpada tuzluluktan etkilenme eşik değerleri olarak kabul edilmektedir. Hiç ürünün alınamadığı durumdaki eşik değerler ise $\mathrm{EC}_{\mathrm{e}}$ için $28 \mathrm{dS} / \mathrm{m}$ ve $E C_{i}$ için ise $19 \mathrm{dS} / \mathrm{m}$ olarak bildirilmektedir. Bu çalışmada, eski ve yeni geliştirilmiş iki sıralı arpa çeşitlerinin farklı sulama suyu tuzluluğu koşullarında, laboratuar şartlarında çimlendirme testine tabi tutulmuştur.

\section{Materyal ve Yöntem}

Çalışma, Çanakkale Onsekiz Mart Üniversitesi Ziraat Fakültesi Tarımsal Yapılar ve Sulama Bölümü Uygulama laboratuarında, 2017 yılında gerçekleştirilmiştir. Araştırmada, biri eski (Cumhuriyet) diğeri yeni (Ince 04) 2 adet iki sıralı arpa

tohumu kullanılmıştır. Uygulama; tesadüf parsellerinde, bölünmüş parseller deneme deseninde, 4 tekrarlamalı olarak gerçekleştirilmiştir. Çalışmada Cumhuriyet ve İnce 04 iki sıralı arpa çeşitleri materyal olarak kullanılmıştır.

Çalışmada, sulama sularının SAR değerleri 3'ten küçük olacak şekilde ayarlanmıştır. Farklı tuz çeşitleri ( $\mathrm{NaCl}, \mathrm{MgSO}_{4}, \mathrm{CaCl}_{2}$ ) kullanılarak farklı ECi'e (Kontrol, 2, 4, 6, 8, 12, $16 \mathrm{dS} / \mathrm{m}$ ) sahip sulama suları oluşturulmuştur. Ayrıca uygulanan sulama suları hazırlanırken $\mathrm{Ca} / \mathrm{Mg}$ oranının 2'den büyük olmasına özen gösterilmiştir. Arpa tohumları deneme başında \%5'lik HCl çözeltisinde sterilize edilmiştir. Daha sonra her petri kabında aynı çeşit arpa tohumu bulunması koşuluyla 10'ar adet arpa tohumu; içerisinde Watman 1 no'lu filtre kâğıdı bulunan petri kaplarına yerleştirilmiştir. Söz konusu kapların her birine tuzlu sulama suyu konusundan $15 \mathrm{ml}$ çimlenme suyu ilave edilmiştir. Daha sonra petri kaplarının kapakları kapatılmış; evaporasyonu önlemek amacıyla da petri kapları parafilm ile kaplanmıştır.

Laboratuar ortamında petri kabında çimlenmeye bırakılan tohumlar 5 gün süreyle takip edilmiş; 3. gün ile 5. gün çimlenen tohumlar yaklaşık olarak aynı saatlerde sayılmıştır. Wang ve ark., (2009) ve Kuşvuran (2015)'in önerileri doğrultusunda kökçük göründükten sonra tohumun çimlendiği kabul edilmiştir. 5. gün sonunda petri kapları açılmış ve çimlenen tohumların kök uzunlukları bir cetvel yardımıyla ölçülmüştür. Daha sonra her petri kabı için kök veren tohumlar, bir kese kâğıdının içerisine yerleştirilerek yaş ağırlıkları ölçülmüştür. Sonra bitkiler 48 saat boyunca $50^{\circ} \mathrm{C}$ 'lik etüvde kurutulup, kuru ağırlıkları ölçülmüştür.

Her petri kabında çimlenen tohumlar Atak ve ark., (2006)'nın önerdiği şekilde yüzdeye çevrilmiştir. Denemenin üçüncü gününde gerçekleşen çimlenme oranı "çimlenme hızı", beşinci gününde elde edilen çimlenme oranı ise "çimlenme gücü" olarak değerlendirilmiştir. Çalışma sonunda elde edilen veriler JMP 11 istatistik paket programı yardımıyla analiz edilmiş ve önemli olan parametreler Student's t testi ile karşılaştırılmıştır.

\section{Bulgular ve Tartışma Çimlenme hızındaki azalma}

Çimlenme hızındaki azalmalar arasındaki farklara yapılan analiz sonucunda uygulama ve çeşitler arasındaki farklar \%1 önem düzeyinde, uygulama $x$ çeşit interaksiyonu ise \%5 önem düzeyinde anlamlı olduğu bulunmuştur. Söz konusu parametrelere yapılan Student's $t$ istatistiği sonucu oluşan gruplar Çizelge 1'de ve Çizelge 2'te gösterilmiştir. Çizelge 1 'den de görüleceği üzere çimlenme hızındaki en fazla azalma, sulama suyu EC değeri $16 \mathrm{dS} / \mathrm{m}$ olan uygulamanın yapıldığı konuda $\% 70$ olarak gerçekleşmiştir. Bunu sulama suyu EC değeri 12 $\mathrm{dS} / \mathrm{m}^{\prime}$ lik uygulama $\% 38.75^{\prime}$ lik oranla takip etmiştir. Çizelge 2'te görüleceği üzere çimlenme hızındaki azalma 1. çeşit olan Cumhuriyette $\% 46,79^{\prime}$ luk bir oranda belirlenirken 2. çeşit olan İnce 04 'de ise bu oran \%20 olarak ölçülmüştür.

Çizelge 1. Sulama suyu EC değerlerinin çimlenme hızındaki azalmaya etkisi

\begin{tabular}{cc}
\hline$E C_{i}(\mathbf{d S} / \mathbf{m})$ & Çimlenme hızındaki azalma (\%) \\
\hline 0 - Kontrol & $0.00 \mathrm{c}^{*}$ \\
2 & $31.25 \mathrm{~b}$ \\
4 & $28.75 \mathrm{~b}$ \\
6 & $32.50 \mathrm{~b}$ \\
8 & $32.50 \mathrm{~b}$ \\
12 & $38.75 \mathrm{~b}$ \\
16 & $70.00 \mathrm{a}$ \\
\hline
\end{tabular}

* Farklı harfler farklı sınıfları göstermektedir.

Uygulama çeşit interaksiyonuna ilişkin sonuçlar Çizelge 3'te gösterilmiştir. Söz konusu çizelgeden de görüleceği gibi çimlenme hızındaki en yüksek azalma 
sulama suyu EC değerinin en yüksek olduğu $(16 \mathrm{dS} / \mathrm{m})$ konuda Cumhuriyet çeşidinde \%87.50 olarak meydana gelmiştir. Bunu sulama suyu EC değeri 12 $\mathrm{dS} / \mathrm{m}$ ile yine aynı çeşit olan Cumhuriyet çeşidi \%60'। oranla takip etmektedir. Her iki konuya ilişkin harflerin farklı olması, konularda meydana gelen değişimlerin istatistiksel olarak anlamlı ölçüde birbirlerinden farklı olmasından kaynaklanmaktadır. Yine aynı çizelgeden görülebileceği üzere, İnce 04 çeşidine uygulanan sulama suyu EC değeri $16 \mathrm{dS} / \mathrm{m}$ ve Cumhuriyet çeşidine uygulanan sırasıyla EC'leri $8 \mathrm{dS} / \mathrm{m}, 6 \mathrm{dS} / \mathrm{m}$ ve $2 \mathrm{dS} / \mathrm{m}$ konularında meydana gelen çimlenme hızındaki azalmalar, aynı sınıfta yer almışlardır. Artan sulama suyu tuzluluğuna karşılık azalan çimlenme hızı değerleri Huang ve Redmann, (1995); Pancholi ve ark., (2001); Prazak (2001); Şenay ve ark. (2005); Kara ve ark. (2011); Benlioğlu ve Özkan (2015) araştırmacıların elde ettikleri sonuçlarla benzerlik göstermektedir.

Çizelge 2. Çeşit bazında çimlenme hızındaki azalmalar

\begin{tabular}{cc}
\hline Çeşit & Çimlenme hızındaki azalma (\%) \\
\hline Cumhuriyet & $46.78 \mathrm{a}$ \\
İnce 04 & $20.0 \mathrm{~b}$ \\
\hline
\end{tabular}

Çizelge 3. Sulama suyu EC'si ile arpa çeşitlerinin interaksiyonu

\begin{tabular}{lc}
\hline $\begin{array}{c}\mathrm{EC}_{\mathbf{i}} / \text { çeşit } \\
\text { etkileşimi }\end{array}$ & $\begin{array}{c}\text { Çimlenme hızındaki azalma } \\
\text { (\%) }\end{array}$ \\
\hline 16, Cumhuriyet & $87.50 \mathrm{a}$ \\
12, Cumhuriyet & $60.00 \mathrm{~b}$ \\
16, İnce04 & $52.50 \mathrm{bc}$ \\
8, Cumhuriyet & $52.50 \mathrm{bc}$ \\
6, Cumhuriyet & $45.00 \mathrm{bc}$ \\
2, Cumhuriyet & $42.50 \mathrm{bc}$ \\
4, Cumhuriyet & $40.00 \mathrm{c}$ \\
2, İnce04 & $20.00 \mathrm{~d}$ \\
6, İnce04 & $20.00 \mathrm{~d}$ \\
12, İnce04 & $17.50 \mathrm{de}$ \\
4, Ince04 & $17.50 \mathrm{de}$ \\
8, İnce04 & $12.50 \mathrm{de}$ \\
0, Ince04 & $0.00 \mathrm{e}$ \\
0, Cumhuriyet & $0.00 \mathrm{e}$ \\
\hline
\end{tabular}

\section{Çimlenme gücündeki azalma}

Çimlenme gücündeki değişim dikkate alındığında hem uygulamalar hem de çeşitler arasındaki farklar \%1 önem düzeyinde anlamlı bulunmuştur. Söz konusu parametrelere yapılan Student's $t$ istatistiği sonucu oluşan gruplar Çizelge 4 ve Çizelge 5 'te gösterilmiştir. Çizelge $4^{\prime}$ ten de görüleceği üzere en fazla çimlenme gücündeki azalma, sulama suyu EC'si $16 \mathrm{dS} / \mathrm{m}$ olarak uygulanan konuda \%63.75 olarak gerçekleşmiştir. Bunu EC'si 12 dS/m lik uygulama $\% 35^{\prime}$ lik oranla takip etmiştir. Çizelge $5^{\prime} \mathrm{da}$ görüleceği üzere çimlenme gücündeki azalma Cumhuriyet çeşidinde \%41.79 ve İnce04 çeşidinde ise çimlenme gücündeki azalma $\% 18.21$ olarak belirlenmiştir.

Çizelge 4. Sulama suyu EC değerlerinin çimlenme gücündeki azalmaya etkisi

\begin{tabular}{cc}
\hline $\mathrm{EC}_{\mathbf{i}}(\mathrm{dS} / \mathrm{m})$ & Çimlenme gücündeki azalma (\%) \\
\hline $0-$ Kontrol & $0.00 \mathrm{c}$ \\
2 & $30.00 \mathrm{~b}$ \\
4 & $27.50 \mathrm{~b}$ \\
6 & $26.25 \mathrm{~b}$ \\
8 & $27.50 \mathrm{~b}$ \\
12 & $35.00 \mathrm{~b}$ \\
16 & $63.75 \mathrm{a}$ \\
\hline
\end{tabular}

Çizelge 5. Çimlenme gücündeki azalmaların çeşitler arasındaki farkı

\begin{tabular}{cc}
\hline Çeşit & Çimlenme gücündeki azalma (\%) \\
\hline Cumhuriyet & $41.79 \mathrm{a}$ \\
Ince 04 & $18.21 \mathrm{~b}$ \\
\hline
\end{tabular}

Çimlenme hızı ve çimlenme gücündeki azalma en fazla sulama suyu EC'si $16 \mathrm{dS} / \mathrm{m}$ olan konularda meydana gelmiştir. Sulama suyundaki tuzluluk miktarı arttıkça, çimlenme hızı ve çimlenme gücü giderek azalmaktadır. Elde edilen sonuçlar, Huang ve Redmann, (1995); Pancholi ve ark., (2001); Prazak (2001); El Madidi ve ark., (2004); Şenay ve ark. (2005); Kara ve ark. (2011); Benlioğlu ve Özkan (2015) tarafından yapılan çalışmalarla benzerlik göstermektedir.

\section{Kök uzunluğundaki değişim}

Çimlenen tohumların kök uzunluklarındaki değişim, uygulamalar bakımından \%1 önem düzeyinde anlamlı bulunmuştur. Söz konusu parametrelere yapılan Student's t istatistiği sonucu oluşan gruplar Çizelge 6 'de gösterilmiştir. Görüleceği üzere en fazla kök uzunluğu kontrol uygulamasının yapıldığı konuda $39,31 \mathrm{~mm}$ olarak gerçekleşmiştir. Bunu sulama suyu EC'si $2 \mathrm{dS} / \mathrm{m}$ olan konu $35.30 \mathrm{~mm}$ takip etmiştir. En kısa kök uzunluğu, sulama suyu EC'si $16 \mathrm{dS} / \mathrm{m}$ olan konuda $16.19 \mathrm{~mm}$ olarak ölçülmüştür. Yapılan uygulamalara bağlı olarak elde edilen sonuçlar Benlioğlu ve Özkan (2015) ve El Madidi ve ark., (2004) 
tarafından yürütülen çalışmalarla benzerlik göstermektedir.

Çizelge 6. Sulama suyu EC değerlerindeki artışın kök uzunluğuna etkisi

\begin{tabular}{cc}
\hline $\mathrm{EC}_{\mathbf{i}}(\mathbf{d S} / \mathbf{m})$ & Kök uzunluğu $(\mathbf{m m})$ \\
\hline $0-$ Kontrol & $39.31 \mathrm{a}$ \\
2 & $35.30 \mathrm{ab}$ \\
4 & $28.43 \mathrm{bc}$ \\
6 & $24.53 \mathrm{~cd}$ \\
8 & $27.97 \mathrm{bc}$ \\
12 & $17.82 \mathrm{~d}$ \\
16 & $16.19 \mathrm{~d}$ \\
\hline
\end{tabular}

\section{Yaş ağırlık}

Yaş ağırlıktaki değişimler hem uygulamalar arasındaki farklarda hem de çeşitler arasındaki farklarda \%1 önem düzeyinde anlamlı bulunmuştur. Söz konusu parametrelere yapılan Student's t istatistiği sonucu oluşan gruplar Çizelge 7 ve Çizelge $8^{\prime}$ de gösterilmiştir. Çizelge 7'de de görüleceği üzere en fazla yaş ağırlık kontrol konusunda 1,532 g olarak ölçülmüştür. Bunu sulama suyu $\mathrm{EC}^{\prime}$ si $2 \mathrm{dS} / \mathrm{m}$ olan uygulama 1.529 g ile takip etmiştir. En düşük yaş ağırlık sulama suyu EC'si $16 \mathrm{dS} / \mathrm{m}$ olan konuda $0.551 \mathrm{~g}$ olarak ölçülmüştür. Çeşitler dikkate alındığında ince 04 çeşidi 1.427 g ile ilk sırada yer alırken Cumhuriyet çeşidi $0.950 \mathrm{~g}$ ile onu takip etmiştir. Yaş ağırıklara ilişkin elde edilen bulgular Benlioğlu ve Özkan (2015) tarafından yapılan çalışmada elde edilen sonuçlarla uyum göstermektedir.

Çizelge 7. Sulama suyu EC değerlerinin çimlenen tohumların yaş ağırlıklarına etkisi

\begin{tabular}{cc}
\hline $\begin{array}{c}\text { Sulama suyu EC değerleri } \\
\text { (dS/m) }\end{array}$ & $\begin{array}{c}\text { Yaş ağırlık } \\
\text { ortalaması (gr) }\end{array}$ \\
\hline $0-$ Kontrol & $1.532 \mathrm{a}$ \\
2 & $1.529 \mathrm{a}$ \\
4 & $1.363 \mathrm{ab}$ \\
6 & $1.217 \mathrm{bc}$ \\
8 & $1.168 \mathrm{bc}$ \\
12 & $0.957 \mathrm{c}$ \\
16 & $0.551 \mathrm{~d}$ \\
\hline
\end{tabular}

Çizelge 8. Çeşitlerin yaş ağırlıkları arasındaki farklar

\begin{tabular}{cc}
\hline Çeşit & Yaş ağırlık ortalaması (gr) \\
\hline Cumhuriyet & $0.950 \mathrm{~b}$ \\
İnce 04 & $1.427 \mathrm{a}$ \\
\hline
\end{tabular}

\section{Kuru ağırlık}

Uygulamaların kuru ağırlık üzerine etkileri istatistiksel olarak \%5 önem düzeyinde etkili olurken; çeşitlere olan etkisi \%1 önem düzeyinde önemli bulunmuştur. Söz konusu farklar Student's t testine tabii tutulmuş ve oluşan gruplar Çizelge 9 ve $10^{\prime} \mathrm{da}$ sunulmuştur. Çizelge $9^{\prime}$ dan da görüldüğü gibi sulama suyu EC'si $12 \mathrm{dS} / \mathrm{m}^{\prime}$ ye kadar olan konuların kuru ağırlıkları aynı sınıfta yer alırken, sulama suyu EC'si 16 $\mathrm{dS} / \mathrm{m}$ olan konuda saptanan kuru ağırlık, uygulamanın etkisiyle azalarak farklı bir sınıfta yer almıştır. En yüksek kuru ağırlık $6 \mathrm{dS} / \mathrm{m}$ iletkenliğe sahip sulama suyunun uygulandığı konuda $0.263 \mathrm{~g}$ olarak ölçülmüştür. Bunu $0.261 \mathrm{~g}$ ile $4 \mathrm{dS} / \mathrm{m}^{\prime}$ lik uygulama takip etmiştir. Kontrol konusunda 0.240 g olarak kuru ağırlık belirlenmiştir. Sulama suyu EC'si 4.6 ve $8 \mathrm{dS} / \mathrm{m}$ olan konuların kuru ağırlıklarının kontrol konusundan fazla olmasının nedeni, sulama suyundaki tuzların, gübre etkisi göstermesi olarak değerlendirilmiştir. Kuru kök ağırlıklarındaki değişimlere ilişkin elde edilen sonuçlar, Benlioğlu ve Özkan (2015); Yıldız ve Terzi (2011) ve El Madidi ve ark., (2004) tarafından yapılan çalışmalarla uyum içerisindedir.

Çizelge 9. Sulama suyu tuzluluğunun kuru ağırlığa etkileri

\begin{tabular}{cc}
\hline $\begin{array}{c}\text { Sulama suyu EC değerleri } \\
\text { (dS/m) }\end{array}$ & $\begin{array}{c}\text { Ortalama kuru } \\
\text { ağırlık (gr) }\end{array}$ \\
\hline $0-$ Kontrol & $0.238 \mathrm{a}$ \\
2 & $0.236 \mathrm{a}$ \\
4 & $0.261 \mathrm{a}$ \\
6 & $0.263 \mathrm{a}$ \\
8 & $0.240 \mathrm{a}$ \\
12 & $0.226 \mathrm{a}$ \\
16 & $0.136 \mathrm{~b}$ \\
\hline
\end{tabular}

Çizelge 10. Kuru ağırlıktaki değişimler için çeşit ortalamalarının çoklu karşılaştırma testi (Student's t) sonuçları

\begin{tabular}{cc}
\hline Çeşit & Ortalama kuru ağırlık (gr) \\
\hline Cumhuriyet & $0.189 \mathrm{~b}$ \\
Ince 04 & $0.267 \mathrm{a}$ \\
\hline
\end{tabular}

\section{Sonuç ve Öneriler}

Bilindiği gibi arpa, tür olarak tuz stresine dayanıklı bir bitki olarak bilinmektedir. Sulama suyu EC sınır değeri dikkate alındığında $5.3 \mathrm{dS} / \mathrm{m}$ ve toprak çamur süzüğü sınır değeri dikkate alındığında $8 \mathrm{dS} / \mathrm{m}$ üst sınır olarak belirtilmektedir. Söz konusu sınır değerlerin üzerindeki koşullarda arpa veriminde azalma beklenir. Yapılan bu çimlendirme çalışmasında 
yeni geliştirilen arpa çeşitlerinden olan İnce 04 çeşidi sulama suyu elektriksel iletkenliğinin $12 \mathrm{dS} / \mathrm{m}$ dahil çimlenmede tolerans gösterdiği belirlenmiştir. Buna karşılık Cumhuriyet çeşidi $8 \mathrm{dS} / \mathrm{m}$ EC değerine kadar çimlenebilme toleransı gösterebilmiştir. Sonuç olarak, çimlenebilmeleri için gerekli sulama suyu elektriksel iletkenlik değeri dikkate alındığında yeni çeşit olan İnce 04'ün sulama suyu tuzluluğuna karşı, eski çeşit olan Cumhuriyet çeşidine göre daha dayanıklı olduğu belirlenmiştir. Sulama suyu elektriksel iletkenlik değeri $12 \mathrm{dS} / \mathrm{m}$ ve sulama suyu SAR değeri 3'den küçük olduğu koşullarda İnce04 çeşidinin yeterli düzeyde çimlenme gösterebileceği söylenebilir. Ayrıca, gelecekte yapılacak ıslah çalışmalarında söz konusu çeşidin genetik materyal olarak kullanılabileceği düşünülmektedir.

\section{Kaynaklar}

Al-Karaki, G.N. 2001. Germination, sodium and potassium concentrations of barley seeds as influenced by salinity. Journal of Plant Nutrition, 24(3): 511-522.

Atak, M., Kaya, M.D., Kaya, G., Kıllı, Y., Çiftçi, C.Y. 2006. Effects of $\mathrm{NaCl}$ on the Germination, Seedling Growth and Water Uptake of Triticale. Turk J. Agric. For. 30: 39-47.

Ayers, R.S., Westcot D.W. 1994. Water Quality for Agriculture. FAO Irrig. And Drain. Paper No.29. Rome, 1989.

Ayyıldız, M. 1990. Sulama Suyu Kalitesi ve Tuzluluk Problemleri. Ankara Ü. Zir. Fak. Yayınları, Yayın No:1130, Sayfa No: 65-66, Ankara.

Benlioğlu, B., Özkan, U. 2015. Bazı arpa çeşitlerinin (Hordeum vulgare L.) Çimlenme dönemlerinde farklı dozlardaki tuz stresine tepkilerinin belirlenmesi. Tarla Bitkileri Merkez Araştırma Enstitüsü Dergisi, 24(2): 109-114.

Çulha, Ş., Çakırlar, H. 2011. Tuzluluğun bitkiler üzerine etkileri ve tuz tolerans mekanizmaları. Afyon Kocatepe Üniversitesi Fen ve Mühendislik Bilimleri Dergisi, 11(2): 11-34.

El Madidi, S., El Baroudi, B., Aameur, F.B. 2004. Effects of salinity on germination and early growth of barley (Hordeum vulgare L.) cultivars. International Journal of Agriculture \& Biology, 6(5): 767-770.

Huang, J., Redmann, R.E. 1995. Salt tolerance of hordeum and brassica species during germination and early seedling growth. Can J. Plant Sci., 815-819.

Kara, B., Akgün, i., Altındal, D. 2011. Tritikale genotiplerinde çimlenme ve fide gelişimi üzerine tuzluluğun ( $\mathrm{NaCl}$ ) etkisi. Selçuk Tarım ve Gıda Bilimleri Dergisi, 25(1): 1-9.

Kuşvuran, A. 2015. The effects of salt stress on the germination and antioxidative enzyme activity of Hungarian vetch (Vicia pannonica Crantz.) varieties. Agricultural Research Communication Centre, 38(1): 51-59.

Maas, E.V., Hoffman, G.J. 1977. Crop salt tolerance current assessment. J. Irrig. and Drainage Div., ASCE 103(IR2): 115-134.

Pancholi, S.R., Bhargava S.C. and Singh. A.K., 2001. Screening of wheat genotypes at different salinity levels for germination percentage. Annals of Agricultural Biological Research, 6(1); 53-55.

Prazak, R. 2001. Salt tolerance of Triticum Monococcum L.. T. dicoccum (Schrank) Schubl. T. durum Desf. and T. aestivum L. seedlings. Journal of Applied Genetics, 42(3): 289-292.

Sönmez, B., Beyazgül, M. 2008. Türkiye'de tuzlu ve sodyumlu toprakların ıslahı ve yönetimi. Sulama ve Tuzlanma Konferansı, 12-13 Haziran 2008, Şanlıurfa.

Şenay, A., Kaya, M.D., Atak, M., Çiftçi, C.Y. 2005. Farklı Tuz konsantrasyonlarının bazı ekmeklik buğday çeşitlerinin çimlenme ve fide gelişimi üzerine etkileri. Tarla Bitkileri Merkez Araştırma Enstitüsü Dergisi, 14(1-2): 50-55.

Taş, İ., 2017. Su Kirliliğinin Tarıma Etkileri. Gübreleme ve Sulama. Tarım Türk dergisi. Sayı 63. 39-43.

Taş, I., Kırnak, H. 2001. Harran Ovasında sulama sonrasında tuzluluk ve taban suyu durumu. GAP II. Tarım Kongresi, s.783-792, Şanlıurfa, 2001.

Wang, W.B., Kim, Y.H., Lee, H.S., Kim, K.Y., Deng, X.P., Kwak, S.S. 2009. Analysis of Antioxidant enzyme activity during germination of alfalfa under salt and drought stresses. Plant Physiology and Bioch., 47(7): 570-577.

Yıldız, M., Terzi, H. 2011. Türkiye'de ekimi yapılan bazı arpa çeşitlerinde erken fide evresi tuz toleransının belirlenmesi. Tarım Bilimleri Dergisi, 17(2011): 1-9.

Yurtseven, E. 1997. Ülkemiz nehir su kaynaklarının kalite değerlendirmesi. VI. Ulusal Kültürteknik Kongresi Bildirileri, 5-8 Haziran 1997, Kirazlıyayla, Bursa, s. 453-459.

Yurtseven, E., Öztürk, H.S. 2001. Sulama suyu tuzluluğunun tınlı toprakta profil tuzluluğuna etkisi. Tarım Bilimleri Dergisi, 7(3): 1-8. 